\title{
Reconsidering the role of photoperiod in relation to effects of precipitation and food availability on spring departure of a migratory bird
}

Along with many current studies investigating the impact of climatic change on the behavioural patterns of migratory birds, the paper by Studds \& Mara [1] demonstrates relationships between environmental conditions and timing of departure from an overwintering site-Font Hill Nature Preserve in southwestern Jamaica - of the American Redstarts (Setophaga ruticilla), a Neotropical-Nearctic migrant. This study adds new information of how the specific conditions of rainfall and food availability-insect abundanceexperienced on the tropical non-breeding grounds can modify the endogenous timing mechanism regulating departure at the time of spring migration. The authors point out that studies investigating the role of climate change in the tropics and migratory schedules have heretofore received little attention because of the insinuation in the literature that circannual rhythms require no environmental input $[2,3]$. However, endogenous oscillators are entrained by the Zeitgeber of seasonal photoperiod that regulates onset of the vernal migratory programme [4]. Given this as background and recent studies identifying climatic conditions, namely rainfall in the tropics are related to migrant arrival on breeding grounds in spring $[5,6]$, the authors have gone ahead to investigate the role of environmental parameters at departure from the wintering grounds.

The authors' claim their results challenge the hypothesis that photoperiod alone regulates the onset of migration. However, few, if any, have actually made such a statement. As stated, this point is misleading. Granted the authors are using this premise as a straw man; yet the discussion as presented suggests a lack of understanding of how photoperiod, and other cues, influence vernal migration. It should be noted that photoperiod plays an instrumental role both as a driver and a Zeitgeber for endogenous circannual rhythms initiating the developmental phase of vernal migration and possibly that of autumn for birds [7-12] as well as the timing of migration and oestrous cycling in an arctic mammal, the reindeer (Rangifer tarandus) [13]. For long-distance, transequatorial migrants, the most convincing data for the role of circannual oscillators are from earlier studies $[4,14]$, who expose captive birds to a $12 \mathrm{~L}$ : $12 \mathrm{D}$ photocycle and demonstrate continuous cycles of gonadal growth, molt and migratory restlessness or Zugunruhe (nocturnal locomotor activity that represents migratory flight). These studies point to the fact that for

The accompanying reply can be viewed at http://dx.doi.org/10.1098/ rspb.2011.2024. birds, who overwinter in photoperiods of one hemisphere that are not relevant to those experienced on the breeding grounds of the other, endogenous circannual rhythms that rely on photoperiod as a Zeitgeber are operating.

American Redstarts in Studds \& Marra [1] overwinter at sites just south of the Tropic of Cancer at a latitude of $18^{\circ} 15^{\prime} \mathrm{N}$ and longitude of $77^{\circ} 30^{\prime} \mathrm{W}$ where the annual change in photoperiod is $2.09 \mathrm{~h}$ (NOAA website). It is known that tropical birds are capable of responding to small changes in photoperiod. For example, the spotted antbird (Hylophylax n. naevioides) in Panama $\left(9^{\circ} \mathrm{N}\right.$ $79^{\circ} \mathrm{W}$ ) experiences an annual change in photoperiod of only $1 \mathrm{~h}$ and is able to respond to an increase of the light period of only $17 \mathrm{~min}$ to initiate development of the breeding stage [15]. Thus, it is likely the increase in photoperiod at the Jamaican site that the Redstarts experience in spring may be sufficient to induce preparations for both the migratory and breeding stages.

As this paper discounts the role of photoperiod in spring departure, I encourage the authors to consider the following. From the work on many north temperate migratory passerines $[7,8,11,16]$, photoperiod has been shown to act as initial predictive factor during the spring stage initiating the developmental phase of migration: changes in hormone secretions regulate alterations in feeding leading to hyperphagia, fattening and hypertrophy of flight muscles. Once in place, birds are in migratory disposition and can depart; however, factors influencing actual departure have little if anything to do with photoperiod per se. Rather, it is the local predictive conditions that include factors, such as wind speeds and direction, precipitation, food resources, social interactions, etc. that affect actual departure ([17], M.R., J. M. Cornelius \& B. Helm, unpublished data, 2011). So, to assert this study has discounted the regulation photoperiod with onset of migration, which I take to mean the authors' interpretation as actual departure biology, is misleading. Given that the migration sub-stages are made up of these three phases: development, mature capability (that allows onset) and termination, each with its own set of regulatory mechanisms $[9,10]$, it would be more appropriate to describe their findings as the cumulative results of environmental conditions; i.e. rainfall, insect abundance as influencing actual migratory departure, but dependent upon prior exposure to increasing day length. This would be a far more accurate assessment of their fascinating system and provide a basis for further meaningful experimental tests. 
The authors rely on Akaike's information criteria (AIC) weights (wi) to determine which variables affect timing of departures from the wintering grounds. Rainfall and arthropod abundance are identified as significant variables, whereas photoperiod is not. This is an example of where simple correlations can result in potentially misleading conclusions. Because photoperiod has been identified as an initial predictive cue in regulation of vernal migration it is possible, indeed probable, that variations in local predictive cues regulating departure may mask correlations with photoperiod. Nonetheless, increasing day length in spring may still be crucial to regulate migratory disposition so as to allow departure. The data tested in this study do not address this point and any conclusion that photoperiod is not involved is not tenable at present.

The study is correlative in terms of ascertaining the relationships between the variables and departure times and then testing for relevance with AIC. Correlations must be confirmed by controlled experimental manipulation. Furthermore, the null hypothesis is based on faulty assumptions. To actually test for photoperiod, one would need to expose birds to short (winter-like) and long (summer-like) days and monitor preparations for migration. At the endogenous rhythm end of the spectrum, it is necessary to run an accurate control by exposing birds to conditions of either constant light or constant dim light, and again determine the timing of preparations for migration. Photoinduction will initiate hyperphagia, fattening and changes in muscle physiology, but probably will not affect departure times. The latter depends on other cues, but those cues likely have no effects in the absence of photostimulation. The author's analyses of their impressive dataset have identified potentially important local predictive cues regulating departure on spring migration but these too need to be confirmed experimentally. The role of photoperiod has not been tested and simple correlations certainly do not provide the whole story.

\section{Marilyn Ramenofsky* \\ Department of Neurobiology, Physiology and Behavior, University of California, One Shields Avenue, Davis, CA 95616, USA *mramenofs@ucdavis.edu}

\section{REFERENCES}

1 Studds, C. E. \& Marra, P. P. 2011 Rainfall-induced changes in food availability modify the departure programme of a migratory bird. Proc. R. Soc. B 278, 3437-3443. (doi:10.1098/rspb.2011.0332)

2 Berthold, P. 2001 Bird migration: a general survey, 2nd edn. Oxford, UK: Oxford University Press.
3 Gwinner, E. 1986 Circannual rhythms: endogenous clocks in the organization of seasonal processes. Berlin, Germany and New York: Springer-Verlag.

4 Gwinner, E. 1996 Circadian and circannual programs in avian migration. F. Exp. Biol. 199, 39-48.

5 Balbontin, J., Moller, A. P., Hermosell, I. G., Marzal, A., Reviriego, M. \& de Lope, F. 2009 Individual responses in spring arrival date to ecological conditions during winter and migration in a migratory bird. F. Anim. Ecol. 78, 981-989. (doi:10.1111/j.1365-2656.2009.01573.x)

6 Saino, N., Szep, T., Romano, M., Rubolini, D., Spina, F. \& Moller, A. P. 2004 Ecological conditions during winter predict arrival date at the breeding quarters in a transSahara migratory bird. Ecol. Lett. 7, 21-25. (doi:10. 1046/j.1461-0248.2003.00553.x)

7 Dawson, A., King, V. M., Bentley, G. E. \& Ball, G. R. 2001 Photoperiodic control of seasonality in birds. F. Biol. Rhythms 16, 365-380. (doi:10.1177/07487300 1129002079)

8 Moore, M. C., Donham, R. S. \& Farner, D. S. 1982 Physiological preparation for autumnal migration in white-crowned Sparrows. Condor 84, 410-419. (doi:10. 2307/1367445)

9 Ramenofsky, M. \& Wingfield, J. C. 2006 Behavioural and physiological conflicts in migrants: the transition between migration and breeding. F. Ornithol. 147, 135-145. (doi:10.1007/s10336-005-0050-4)

10 Ramenofsky, M. 2011 Hormones in migration and reproductive cycles of birds. In Hormones and reproduction in vertebrates (eds D. Norris \& K. H. Lopez), pp. 205-236. New York, NY: Academic Press.

11 Schwabl, H. \& Farner, D. S. 1989 Endocrine and environmental control of vernal migration in male white-crowned sparrows, Zonotrichia l. gambelii. Physiol. Zool. 62, 1-10.

12 Wingfield, J. C., Schwabl, H. \& Mattocks Jr, P. W. 1990 Endocrine mechanisms of migration. In Bird migration (ed. E. Gwinner), pp. 232-256. Berlin, Germany: Springer.

13 Weiqun, L., Qing-Jun, M., Tyler, N. J. C., Stokkan, K.-A. \& Loudon, A. S. I. 2010 A circadian clock is not required in an arctic mammal. Curr. Biol. 20, 533-537. (doi:10.1016/j.cub.2010.01.042)

14 Helm, B., Schwabl, I. \& Gwinner, E. 2009 Circannual basis of geographically distinct bird schedules. F. Exp. Biol. 212, 1259-1269. (doi:10.1242/jeb.025411)

15 Hau, M., Wikelski, M. \& Wingfield, J. C. 1998 A neotropical forest bird can measure the slight changes in tropical photoperiod. Proc. R. Soc. Lond. B 265, 89-95. (doi:10.1098/rspb.1998.0268)

16 Morton, M. L. 2002 The mountain white-crowned sparrow: migration and reproduction at high altitude. Stud. Avian Biol. 24, 1-236.

17 Richardson, W. 1990 Timing of bird migration in relation to weather. In Bird Migration (ed. E. Gwinner), pp. 78-101. Berlin, Germany and New York: Springer-Verlag. 